Journal of Applied Pharmaceutical Science Vol. 5 (10), pp. 080-084, October, 2015

Available online at http://www.japsonline.com

DOI: $10.7324 / J A P S .2015 .501014$

ISSN 2231-3354 (cc) BY-NC-SA

\title{
Phenylalanine enhances Quercetin content in In vitro cultures of Abutilon indicum L.
}

\author{
Ramgopal Rao Sajjalaguddam*, Anitha Paladugu \\ Department of Biotechnology, Sreenidhi Institute of Science and Technology (Autonomous), Yamnampet, Ghatkesar, Hyderabad-501301, Telangana, India.
}

\begin{tabular}{|c|c|}
\hline ARTICLE INFO & ABSTRACT \\
\hline Article history: & \multirow{9}{*}{$\begin{array}{l}\text { Flavonoids have aroused considerable interest because of their potential beneficial effect on human health. } \\
\text { Quercetin is one of the most abundant natural flavonoids present in medicinal plants. In the present study, a } \\
\text { comparative phytochemical analysis of bioactive compounds from leaf and leaf derived callus of Abutilon } \\
\text { indicum L. was carried out. Thin layer chromatography (TLC) and high performance liquid chromatography } \\
\text { (HPLC) analysis of methanolic extract of Abutilon leaf revealed the presence of quercetin. To test the effect of } \\
\text { precursor in enhancing flavonoid content, in vitro studies were conducted by supplementing phenylalanine to } \\
\text { actively growing callus cultures of Abutilon. More than threefold increase in quercetin content was obtained in } \\
\text { elicitor induced callus compared to control. }\end{array}$} \\
\hline Received on: 07/07/2015 & \\
\hline Revised on: 03/08/2015 & \\
\hline Accepted on: 17/08/2015 & \\
\hline Available online: $28 / 10 / 2015$ & \\
\hline Key words: & \\
\hline Abutilon indicum Callus; & \\
\hline $\begin{array}{l}\text { Flavonoids; Quercetin; } \\
\text { HPLC. Elicitor: }\end{array}$ & \\
\hline $\begin{array}{l}\text { HPLC; Elicitor; } \\
\text { Phenylalanine. }\end{array}$ & \\
\hline
\end{tabular}

\section{INTRODUCTION}

Medicinal plants are the most important source of life saving drugs for the majority of the world's population. Knowledge of the phytochemical constituents is very essential to facilitate search of the actual effectiveness of the plants in medicine. Medicinal plants being seasonal are not always available and hence the quality of metabolites produced by them depends on fluctuations in growing conditions. These herbs are rich source of many phytochemicals including flavonoids. Flavonoids are polyphenolic compounds that are ubiquitous in nature and are categorized according to their chemical structure into flavones, isoflavones, flavon-3-ol and anthocyanins. They have aroused considerable interest because of their potential beneficial effect on human health viz - antidiabetic, anticancer, antiviral, anti allergic, antioxidant, anti-inflammatory, antitumor, anti carcinogenic and anti ageing properties. Abutilon indicum L. (Malvaceae) is distributed in tropical and sub tropical region of

\footnotetext{
* Corresponding Author

Ramgopal Rao Sajjalaguddam, Associate Professor, Department of

Biotechnology, Sreenidhi Institute of Science and Technology

(Autonomous), Yamnampet, Ghatkesar, Hyderabad-501301,

Telangana, India.Email: mail id: sramgopalr@gmail.com
}

India. All parts of the plant have been recognized to have medicinal properties. The plant is used as, anti asthmatic, antiarthritic, cardioprotective, anti-inflammatory, antidiabetic, antiulcer and antioxidant activity, (Reyad-ul-ferdous et al., 2015; Archna et al., 2013). Plant cell cultures offer an alternative approach for production of important secondary metabolites. There are many reports of flavonoid production from plant cell cultures but they suffer from slow growth rate and low productivity issues (Jedinak et. al., 2004). Flavonoids derived from plant cell cultures can be easily separated in polymeric form than those derived from intact plant tissues (Masoumian et. al., 2011; Ong et al.,, 2011; Bandekar and Lele, 2014) Their concentrations can also be significantly enhanced in cell cultures through control of in vitro conditions and precursor feeding to stimulate metabolite production (Lila et al., 2005). In order to enhance the synthesis of secondary metabolites, several organic compounds have been fortified to the medium (Namdeo et al., 2007).

Supplementing precursors, elicitors \& growth promoters have also been shown to increase secondary metabolite content in cell cultures (Preetpal and Navdeep, 2012). It is also evident that any compound, which is an intermediate in or at the beginning of a secondary metabolite biosynthetic pathway, has a fair chance of increasing the yield of the final product. 
Isoflavones and flavonoids originate from phenylalanine, an upstream metabolic precursor through phenylpropanoid pathway. Supplementation of phenylalanine is expected to produce elevated level of target compound (Shinde et al., 2009). Hence, the present study was carried out to optimize the callus growth and study the effect of Phenylalanine on quercetin production in callus cultures of Abutilon indicum.

\section{MATERIALS AND METHODS}

The leaves of A. indicum were collected from SNIST campus, yamnampet, ghatkesar, Hyderabad, washed properly, shade dried, powdered and kept in moisture free container for further use. Leaf explants were excised from young healthy plant and washed with running tap water twice and then with Tween 20 for 2 min. Explants were surface sterilized with $0.1 \%$ of Mercuric chloride for 2 min in laminar air flow, thoroughly washed with sterile distilled water for 7-8 times and were cut in to small pieces. Explants were cultured on Murashige and Skoog (MS) media (Murashige and Skoog, 1962) with 3\% sucrose and 0.8\% agar with different concentration of growth regulators 2,4-Dichloro phenoxy acetic acid (2,4-D) individually or in combination with Indole 3acetic acid (IAA) (Jyotiranjan et al., 2009). The $\mathrm{pH}$ of the media was adjusted to 5.75 and cultures were maintained at $25^{\circ} \mathrm{C}$ under dark conditions. Well established callus derived from $\mathrm{MS}+2,4-\mathrm{D}$ $(2 \mathrm{mg} / \mathrm{l})$ and IAA $(0.4 \mathrm{mg} / \mathrm{l})$ was then grown in presence of various concentrations of phenylalanine (PA) with a control treatment not containing PA. Callus growth and quercetin content was analyzed by harvesting $2,4,6$, and 8 weeks old callus.

\section{Extraction of Phytochemicals from leaf and leaf derived Callus}

$15 \mathrm{gm}$ of the leaf and $5 \mathrm{gm}$ of leaf derived callus were placed separately inside the thimble of soxhlet extractor. $80 \mathrm{ml}$ of methanol, 20ml of distilled water (ratio 80:20) was added in the reservoir, with an extraction temperature of $70^{\circ} \mathrm{C}$. After seven hours and four cycles of extraction, the extract was filtered using Whatmann filter paper and preliminary phytochemical screening was carried out using standard screening methods (Kokate C K, 2014).

\section{TLC}

Methanolic extracts of both leaf and leaf derived callus were then subjected to thin layer chromatography (TLC) for the detection of quercetin using chloroform: methanol (90:10) solvent and anisaldehyde sulphuric acid as spraying agent. Spots of samples and standard quercetin were compared and $\mathrm{Rf}$ values were calculated. Selected spots containing quercetin were pooled together and concentrated for further analysis by high performance liquid chromatography (HPLC).

\section{HPLC}

\section{Sample preparation}

Methanolic extract of leaf was evaporated to dryness and the residue was re-dissolved in $50 \mathrm{~mL}$ distilled water. The extract was then centrifuged at $10,000 \mathrm{rpm}$ for $5 \mathrm{~min}$. The residue was redissolved in Methanol and filtered through a $0.45 \mu \mathrm{m}$ millipore filter.

\section{Chromatographic equipment and conditions}

HPLC analysis of quercetin was carried out as per the method followed by Rajalakshmi and Senthil, 2009. The chromatographic analysis were performed on a $250 \mathrm{~mm} \times 4.6 \mathrm{~mm}$ i.d., C18 (ODS), Shimadzu, Japan with $0.5 \%$ aqueous solution of Orthophosphoric acid and methanol (HPLC Grade, Himedia Laboratories, Mumbai) as mobile phase at a flow rate of $1 \mathrm{~mL}$ min-1. The HPLC equipment comprised Hewlett-Packard (HP) 1050 Chemstation Software, an HP model 35900 interface unit, an HP 9000 Series 300 computer, and an HP DeskJet 500 Printer. A Waters 486 tunable absorbance detector was operated at $254 \mathrm{~nm}$ with a detector sensitivity of 0.05 AUFS. Determinations were performed after three separate extractions of each sample, and each extract was injected separately. Peak area identification of the leaf extract was carried out by comparing the peak area of authentic standard quercetin (RM 6191, Himedia laboratories, Mumbai). By comparing the amount of sample and standard taken for the study with area of sample and standard, the percentage of quercetin in leaf extract was calculated using the formula

Percentage of quercetin in extract $=(\mathrm{Wq} / \mathrm{W}) \mathrm{X}(\mathrm{Ae} / \mathrm{As}) \times 100$ Where

$$
\begin{aligned}
& \mathrm{Wq}=\text { Weighed amount }(\mathrm{mg}) \text { of quercetin in standard solution } \\
& \mathrm{W}=\text { Weighed amount }(\mathrm{mg}) \text { of sample (leaf extract) } \\
& \mathrm{Ae}=\text { Peak area of quercetin from leaf extract } \\
& \text { As }=\text { Peak Area of standard quercetin }
\end{aligned}
$$

\section{Isolation of flavonoids by column chromatography and their estimation}

$1 \mathrm{gm}$ of methanolic extract was dissolved in $20 \mathrm{ml}$ of methanol and mixed with 2 gm of silica gel (60-120 mesh) and dried in vacuum oven at $45^{\circ} \mathrm{C}$. The material was then transferred to the column and gradient elution was carried out by using ethyl acetate, ethyl acetate: methanol, methanol: water in different proportions with an elution rate of $10 \mathrm{ml} /$ minute.

Flavonoid content in the eluted fractions was estimated using shinoda, $\mathrm{Zn}-\mathrm{HCl}$ and ferric chloride tests (Samatha et.al 2012). For shinoda test ( $\mathrm{Mg}-\mathrm{HCl}$ reduction test) $1 \mathrm{mg}$ of test sample was dissolved in alcohol and few fragments of magnesium ribbon were added drop wise along the tube. Pink to red color indicate the presence of flavonoids. In $\mathrm{Zn}-\mathrm{HCl}$ reduction test a mixture of zinc dust was added to the test solution and few drops of concentrated $\mathrm{HCl}$ was added drop wise along the side of the tube. Appearance of red colour indicates the presence of flavonoids. For the ferric chloride test, a freshly prepared ferric chloride solution was added to the test solution. A bluish green to black color indicate the presence of flavonoid.

\section{Quantitative estimation of quercetin}

Quantification of the isolated and identified quercetin in callus samples was carried out by aluminum chloride method at 
$415 \mathrm{~nm}$ using known concentrations of quercetin (Elija et .al 2010) The amount of quercetin in samples was then determined $(\mathrm{mg} / \mathrm{g}$ dry weight) by comparing with that of standard quercetin. Three such replicates were examined and mean values were calculated.

\section{RESULTS}

\section{Callus induction}

Initiation of callus was observed after one week of culture (Fig. 1a). Callus was produced from the entire cut end of leaf explants after 2 weeks of culture (Fig. 1b).
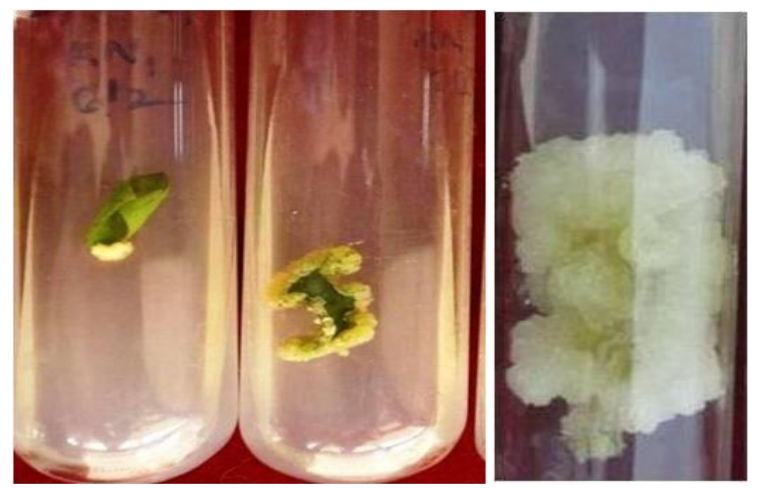

Fig. 1: Callus induction from leaf explants of Abutilon indicum on $\mathrm{MS}+2 \mathrm{mg} / \mathrm{l}$ 2, 4-D + $0.4 \mathrm{mg} / \mathrm{l}$ IAA. a. Callus initiation after one week, b. Callus after two week \& c. fully grown callus.

Table 1: Effect of growth regulators on callus induction from leaf explants of Abutilon on MS medium supplemented with Auxin \& Cytokinin after four week of culture.

\begin{tabular}{|c|c|c|}
\hline $\begin{array}{c}\text { Type of } \\
\text { Phytohormone }\end{array}$ & $\begin{array}{c}\text { Concentration of } \\
\text { 2, 4-D \& IAA (mg/l) }\end{array}$ & $\begin{array}{c}\text { Fresh weight of } \\
\text { Callus (g) }\end{array}$ \\
\hline \multirow{5}{*}{$2,4-\mathrm{D}$} & 0.5 & $0.60 \pm 0.01$ \\
\hline & 1.0 & $0.64 \pm 0.03$ \\
\hline & 1.5 & $0.78 \pm 0.02$ \\
\hline & 2.0 & $0.90 \pm 0.01$ \\
\hline & 2.5 & $0.84 \pm 0.01$ \\
\hline \multirow{25}{*}{$2,4-\mathrm{D}+\mathrm{IAA}$} & $0.5+0.1$ & $0.65 \pm 0.02$ \\
\hline & $1.0+0.1$ & $0.70 \pm 0.03$ \\
\hline & $1.5+0.1$ & $0.75 \pm 0.04$ \\
\hline & $2.0+0.1$ & $1.20 \pm 0.03$ \\
\hline & $2.5+0.1$ & $1.24 \pm 0.02$ \\
\hline & $0.5+0.2$ & $1.31 \pm 0.01$ \\
\hline & $1.0+0.2$ & $1.34 \pm 0.03$ \\
\hline & $1.5+0.2$ & $1.47 \pm 0.01$ \\
\hline & $2.0+0.2$ & $1.50 \pm 0.10$ \\
\hline & $2.5+0.2$ & $1.60 \pm 0.11$ \\
\hline & $0.5+0.3$ & $1.78 \pm 0.21$ \\
\hline & $1.0+0.3$ & $1.86 \pm 0.20$ \\
\hline & $1.5+0.3$ & $2.10 \pm 0.20$ \\
\hline & $2.0+0.3$ & $2.40 \pm 0.15$ \\
\hline & $2.5+0.3$ & $2.51 \pm 0.17$ \\
\hline & $0.5+0.4$ & $2.72 \pm 0.11$ \\
\hline & $1.0+0.4$ & $2.80 \pm 0.15$ \\
\hline & $1.5+0.4$ & $3.10 \pm 0.13$ \\
\hline & $2.0+0.4$ & $3.50 \pm 0.20$ \\
\hline & $2.5+0.4$ & $3.10 \pm 0.10$ \\
\hline & $0.5+0.5$ & $2.41 \pm 0.12$ \\
\hline & $1.0+0.5$ & $2.52 \pm 0.20$ \\
\hline & $1.5+0.5$ & $2.75 \pm 0.16$ \\
\hline & $2.0+0.5$ & $2.7 \pm 0.140$ \\
\hline & $2.5+0.5$ & $2.8 \pm 0.120$ \\
\hline
\end{tabular}

Callus growth in terms of fresh weight was better in dark conditions than under $16 / 8$ photoperiod. Of all the concentrations of auxin tested, maximum callus induction was achieved on MS medium supplemented with $2 \mathrm{mg} / \mathrm{l}$ of 2, 4-D. When auxin containing MS media was supplemented with IAA, it resulted in increase in the callus formation. Maximum callus formation was obtained on MS medium supplemented with $2 \mathrm{mg} / \mathrm{l}$ 2, 4-D and 0.4 mg/l IAA (Figure 1c). Data on callus growth in terms of fresh weight is presented in Table 1 .

\section{Phytochemical analysis of leaf $\&$ leaf derived callus extracts}

Preliminary phytochemical screening of methanolic extract of leaf and leaf derived callus revealed that both Abutilon leaves and leaf derived callus possess alkaloids, flavonoids, tannins and phenolic compounds (Table 2). However, saponins and glycosides were only present in leaf extract but absent in callus extract.

Table 2: Phytochemical analysis of leaf and leaf derived callus extracts of Abutilon.

\begin{tabular}{llcc}
\hline \multirow{2}{*}{ S. no } & \multirow{2}{*}{ Phytochemical Test } & \multicolumn{2}{c}{ Methanolic extract } \\
\cline { 3 - 4 } & & Leaf & Leaf derived Callus \\
\hline 1 & Alkaloids & + & + \\
2 & Flavonoids & + & + \\
3 & Tannins & + & + \\
4 & Phenols & + & + \\
5 & Triterpenoids & - & - \\
6 & Saponins & + & - \\
7 & Glycosides & + & - \\
\hline
\end{tabular}

\section{TLC and HPLC analysis}

Thin layer chromatography of methanolic extract of both Abutilon leaf and leaf derived callus showed presence of quercetin. When the developed plates were sprayed with $5 \%$ ethanolic ferric chloride solution, bluish grey spots were visualized which coincided with that of the standard reference quercetin. Rf value of quercetin isolated from the extracts coincided with the $\mathrm{Rf}$ value of standard quercetin. HPLC spectra of standard quercetin shows peak at retention time of 2.596 in mobile phase with $0.5 \%$ aqueous solution of ortho phosphoric acid and methanol. HPLC spectra of methanolic extract of Abutilon leaf shows peak at the same retention time as compared to standard quercetin. By comparing the amount of sample and standard taken for the study with area of sample and standard, the percentage of quercetin in Abutilon leaf extract was found to be $1.884 \%$.

Percentage of quercetin in extract $=(\mathrm{Wq} / \mathrm{W}) \mathrm{X}(\mathrm{Ae} / \mathrm{As}) \times 100$

$$
\begin{gathered}
=(5 / 10) \times(20278665 / 5380836) \times 100 \\
=1.884 \%
\end{gathered}
$$

Fractions subjected to shinoda test, $\mathrm{Zn}-\mathrm{HCl}$ reduction test and ferric chloride test revealed dark red, red and bluish green color respectively indicating the presence of flavonoids.

\section{Effect of phenylalanine on production of quercetin}

When compared to control callus $(0.14 \mathrm{mg} / \mathrm{g}$ dry weight $)$ quercetin content more than doubled $(0.23$ to $0.47 \mathrm{mg} / \mathrm{g}$ dry weight) when callus was grown on MS media along with various 
concentrations of PA $(25,50,75 \& 100 \mathrm{mg} / 100 \mathrm{ml}$ Media). Of all the concentrations of PA tested for its elicitation effect, maximum quercetin content $(0.47 \mathrm{mg} / \mathrm{g}$ dry weight) was found in four week old callus grown on standardized MS medium fed with $75 \mathrm{mg} / 100$ ml PA (Fig. 2).

This is more than threefold increase in quercetin content when compared to control callus. Further purification (column chromatography) and quantification (HPLC) of callus derived quercetin is to be carried out.

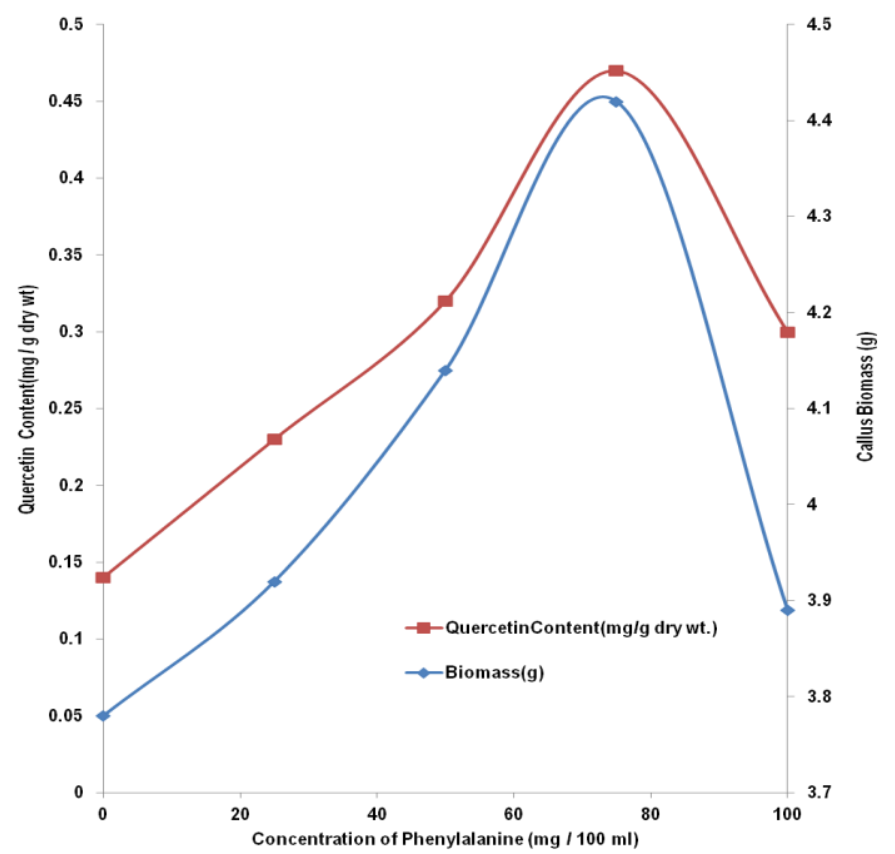

Fig. 2: Effect of phenylalanine on biomass and quercetin production in Abutilon callus.

\section{DISCUSSION}

Bioactive compounds are normally accumulated as a secondary metabolite in all plant cells but their concentration varies according to the plant parts, season, climate, and growth phase. The present study shows that plants and their tissue cultures retain the potential to synthesize flavonoids. Phenylalanine is a precursor of flavonoids and plays an important role in flavonols biosynthesis.

Hence, being one of the precursors of flavonoids, when fed into the MS medium, PA is known to increase the production of flavonoids. In one such study, when Hydrocotyle bonariensis callus was treated with PA at the concentration of $3 \mathrm{mg} / \mathrm{l}$, it successfully triggered the production of flavonoid (Masoumian et. al 2011).

In another study the effect of PA on production of quercetin as exogenous incorporation of phenylalanine in liquid culture increased the yield of total quercetin about 2 to 3 fold in comparison to control (Mahesh et. al 2014). Callus/ suspension culture is an ideal system for production of bioactive compounds like quercetin in Abutilon. In the present study maximum quercetin content was observed in callus grown on MS medium fed with 75 mg PA. From the preliminary results obtained in this study it can be concluded that PA can be used as a precursor for production of medicinally important flavonoids like quercetin. The present study thus proves that accumulation of increased quercetin content in callus cultures can be exploited for its large-scale production for its possible array of health promoting benefits as anti-oxidant, antiinflammatory and anti-cancerous agents in future. To fully realize the potential of this medicinally important secondary metabolite (quercetin derived from Abutilon callus), further studies of purification (Column chromatography), characterization (HPLC) and scale up are required.

\section{ACKNOWLEDGEMENTS}

Authors thank the management and leadership of Sreenidhi Institute of Science and Technology for providing necessary facilities and support.

\section{REFERENCES}

Archna Sharma, Sharma RA, Hemlata Singh. Phytochemical and pharmacological profile of Abutilon indicum L. Sweet: A review. Int. J. Pharm. Sci. Rev. Res, 2013; 20: 120-127.

Bandekar H, S. S. Lele. Production of flavonol quercetin from cultured plant cells of Banyan (Ficus benghalensis L). International Journal of Innovative Research in Science Engineering and Technology, 2014; 3(5): 12150-12157.

Elija Khatiwora, Vaishali B. Adsul, Manik M. Kulkarni, N.R. Deshpande, Kashalkar RV. Spectroscopic determination of total phenol and flavonoid contents of Ipomoea carnea. International Journal of ChemTech Research, 2010; 2:1698-1701

Jedinak A, Farago J, Psenakova I, Maliar T.Approaches to flavonoid production in plant tissue cultures. Biologia Bratislava, 2004; 59(6): 697-710

Jyoti Ranjan R, Manorama Mishra, Ritarani Das, Santi Lata Sahoo. In vitro Micropropagation of Abutilon indicum $\mathrm{L}$ through leaf explants. Plant Tissue Cult. \& Biotech. 2009; 19(2): 177-184.

Kokate CK. 2014, Practical Pharmacognosy. $5^{\text {th }}$ Editon, Vallabh Prakashan, New Delhi, pp viii+222.

Lila MA, Yousef GG, Jiang Y, Weaver CM. Flavonoid mixtures from cell cultures. J. Nutr. 2005; 135: 1231-1235.

Mahesh Chand Meena, Rishi Kesh Meena, Vidya Patni. Effect of elicitor on quercetin production in cell cultures of Citrullus colocynthis (Linn.). The Pharma Innovation - Journal, 2014, 3:2.

Masoumian, M., Arbakariya, A., Syahida A, Maziah, M. Effect of precursors on flavonoid production by Hydrocotyle bonariensis callus tissues. African Journal of Biotechnology, 2011; 10:6021-6029.

Murashige T, Skoog F. A revised medium for rapid growth and bio-assays with tobacco tissue cultures. Physiol Plant, 1962; 15: 473-497.

Md. Reyad-ul-ferdous,Mehedi Rahman, Md. Kawsar Mahamud, Sharmi Sultana Aysha, Md. Didaruzzaman Sohel. Pharmacologicals and Phytochemicals Potential of Abutilon indicum: A Comprehensive Review, American Journal of BioScience, 2015; 3: 5-11.

Namdeo AG, Jadhav TS, Rai PK, Gavali S, Mahadik KR. Precursor feeding for enhanced production of secondary metabolites. Pharmacogn. Rev, 2007;1: 227-231.

Ong S.L, Ling APK ,Poospooragi R , S.Moosa. Production of flavonoid compounds in cell cultures of Ficus deltoidea as influenced by medium composition, Int. J. Med. Arom. Plants, 2011;1: 62-74

Preetpal K , Navdeep Singh Bains. Extraction of Flavonoids from In vivo and In vitro tissue culture of some important halophytes of western Rajasthan. International Journal of PharmTech Research, 2012; 4 (3); 1167-1171.

Rajalakshmi PV, Kalaiselvi Senthil K. Direct HPLC analysis of Quercetin in exudates of Abutilon indicum (Linn). Malvaceae. Journal of Pharmaceutical Science and Technology, 2009; 1: 80-83. 
Shinde AN, Malpathak N, Fulzele DP ,Optimized production of isoflavones in cell cultures of Psoralea corylifolia L. using elicitation and precursor feeding. Biotechnol Bioprocess Eng, 2009; 14: 612-618

Samatha T, Srinivas P, Shyamsundarachary R, Rajinikanth M , Rama Swamy N. Phytochemical analysis of seeds, stem bark and root of an endangered medicinal forest tree oroxylum indicum (l) kurz. International Journal of Pharma and Bio Sciences, 2012; 3:1063 - 1075.

How to cite this article:

Ramgopal Rao Sajjalaguddam, Anitha Paladugu. Phenylalanine enhances Quercetin content in In vitro cultures of Abutilon indicum L. J App Pharm Sci, 2015; 5 (10): 080-084. 